DOI: 10.12731/2658-6649-2019-11-5-2-34-39

УДК 616-092.19

\title{
СОСТОЯНИЕ ГЕМОСТАЗА \\ У БОЛЬНЫХ С РАЗНОЙ ЧУВСТВИТЕЛЬНОСТЬЮ К АЦЕТИЛСАЛИЦИЛОВОЙ КИСЛОТЕ ПРИ ИШЕМИЧЕСКОЙ БОЛЕЗНИ СЕРДЦА
}

Гончаров М.Д., Веселов А.Е., Пац Ю.С.

С иелью изучения гемостаза у чувствительных и резистентных $к$ ацетилсалиииловой кислоте (АСК) больных ишемической болезнью сердияа (ИБС) обследовано 53 пациента с ИБС. Больные разделеньл на группь чувствительных и резистентных к АСК. У всех обследованных изучались показатели сосудисто-тромбочитарного гемостаза. Установлено, что у резистентных к АСК больных повымена АДФ-индуцированная агрегаиионная способность тромбоцитов, снижено их количество и повышен уровень фактора Виллебранда.

Ключевые слова: ишемическая болезнь сердиа; ацетилсалициловая кислота; тромбоцитьі; агрегачия.

\section{HEMOSTASIS STATE IN PATIENTS WITH DIFFERENT SENSITIVITY TO ACETYLSALICYLIC ACID IN ISCHEMIC HEART DISEASE}

Goncharov M.D., Veselov A.E., Pats Yu.S.

In order to study hemostasis in sensitive and acetylsalicylic acid (ASA) resistant patients with ischemic heart disease (IHD), 53 patients with IHD were examined. Patients are divided into groups sensitive and resistant to ASA. In all the examined, the parameters of vascular-platelet hemostasis were studied. It was established that in patients with ASA-resistant ADP-induced platelet aggregation capacity was increased, their number was reduced, and von Willebrand factor was increased.

Keywords: coronary heart disease; acetylsalicylic acid; platelets; aggregation. 


\section{Введение}

Ишемическая болезнь сердца является основной причиной смертности, как в России, так и за рубежом. В частности, из-за развития острой ишемии в следствии атеротромбоза [1, 2]. Главным средством профилактики тромбообразования и развития острой ишемии у больных ИБС является антитромбоцитарная терапия. Но зачастую имеет место недостаточный ответ на дезагреганты. В этих случаях речь идет о резистентности к антитромбоцитарым препаратам. Роль сосудисто-тромбоцитарного гемостаза в развитии резистентности к ацетилсалициловой кислоте (АСК) при ИБС не ясна $[2,3]$. Целью исследования явилось изучение особенностей гемостаза у чувствительных и резистентных к АСК больных ИБС.

\section{Материалы и методы исследования}

Обследованы 53 пациента с ИБС (средний возраст 61,1 $\pm 1,1$ лет, 25 мужчин и 28 женщин), не принимавших до госпитализации антиагреганты. Диагноз ИБС устанавливался в соответствии с критериями Европейского общества кардиологов [4]. Всем больным была назначена терапия АСК. Контрольная группа сформирована из 50 относительно здоровых добровольцев сопоставимых по полу и возрасту. До начала лечения больные обследованы и разделены на две группы: чувствительных к АСК (чАСК) и резистентных к АСК (рАСК) [5]. Изучались показатели сосудисто-тромбоцитарного гемостаза: агрегация тромбоцитов, спонтанная и индуцированная, с применением в качестве индукторов АДФ в дозах 0,1 мкМ и 5 мкM и адреналина в дозе 10 мкг/мл на агрегометре «LA230-2 БИОЛА» (Россия). Определялась концентрация фактора Виллебранда (ФВ) в плазме крови. Статистический анализ осуществляли в пакете программ Statistica 7.0 (StatSoftInc. 2004, USA).

\section{Результаты исследования}

При исследовании состояния сосудисто-тромбоцитарного гемостаза обнаружено, что только у группы рАСКв периферической крови снижено содержание тромбоцитов как относительно контрольных значений, так и показателей, выявленных у группы чАСК.У группы рАСК снижается уровень АДФ- (при дозе АДФ в 5 мкМ) и адреналин-индуцированной агрегации тромбоцитов по сравнению с контролем. Также особенностями сосудисто-тромбоцитарного гемостаза у группы рАСК является увеличение уровня фактора Виллебранда. У группы чАСК относительно контрольного диапазона отмечается снижение агрегации тромбоцитов с адреналином. 


\section{Обсуждение}

Известно, что при ИБС имеет место повышенная реактивность тромбоцитов [6]. Резистентность к АСК коррелирует с высоким уровнем АДФ в крови. Это обусловлено генерализованной активацией тромбоцитов и высвобождением АДФ, тромбоксана, повышенным уровнем фактора Виллебранда из-за повреждения эндотелиальных клеток $[7,8]$. При исследовании гемостаза обнаружены выраженные различия сосудисто-тромбоцитарного звена, в зависимости от чувствительности к АСК у больных ИБС. Особенностью сосудисто-тромбоцитарного гемостаза у группы рАСК является увеличение уровня АДФ-индуцированной агрегации тромбоцитов как при дозе АДФ в 0,1 мкМ, так и в 5 мкМ, что определяет повышенную готовность тромбоцитов к агрегации. При этом у группы рАСК риск тромбообразования определяется тем, что на фоне пониженного количества тромбоцитов в периферической крови, в 1,4 раза повышается содержание фактора Виллебранда. Независимо от чувствительности к АКС у больных ИБС значительно понижается адреналин-индуцированная агрегация тромбоцитов.

\section{Заключение}

При исследовании системы гемостаза у больных ИБС в зависимости от чувствительности к АСК обнаружены характерные особенности в состоянии сосудисто-тромбоцитарного гемостаза, выражающиеся в повышении АДФ-индуцированной агрегационной способности тромбоцитов, в снижении их количества и повышении уровня фактора Виллебранда у резистентных к АСК больных.

\section{Список литературы}

1. Bae M.H., Lee J.H., Yang D.H. et al. White blood cell, hemoglobinand platelet distribution width as short-term prognostic markers in patients withacute myocardial infarction. J. Korean Med. Sci., 2014, 29(4), pp. 519-26.

2. Becatti M., Fiorillo C., Gori A.M. et al. Platelet and leukocyte ROS production and lipoperoxidation are associated with high platelet reactivity in Non-ST elevation myocardial infarction (NSTEMI) patients on dual antiplatelet treatment. Atherosclerosis. 2013, 231(2), pp. 392-400.

3. Гринштейн Ю.И., Савченко А.А., Гринштейн И.Ю., Савченко Е.А. Особенности гемостаза, метаболической активности тромбоцитов и частота резистентности к аспирину у больных с хронической сердечной недостаточностью после аортокоронарного шунтирования // Кардиология. 2008. № 6. C. 51-56. 
4. 2013 ESC Guidelines on the Management of Stable Coronary Artery Disease. The Task Force on the management of stable coronary artery disease of the European Society of Cardiology. Russ J Cardiol 2014, 7 (111): 7-79.

5. Гринштейн Ю.И., Филоненко И.В., Савченко А.А. и др. Способ диагностики резистентности к ацетилсалициловой кислоте. Патент № 2413953 РФ, МПК G01N 33/86 (2006.01). Опубл. 10.03.2009, Бюл. № 7: 8 c.

6. Савченко Е.А., Савченко А.А., Герасимчук А.Н., Грищенко Д.А. Оценка метаболического статуса тромбоцитов в норме и при ишемической болезни сердца // Клиническая лабораторная диагностика. 2006. № 5. С. 33-36.

7. Borna C., Lazarowski E., van Heusden C. et al. Resistance to aspirin is increased by ST-elevation myocardial infarction and correlates with adenosine diphosphate levels. Thromb J., 2005; 3:10.

8. Chakroun T., Gerotziafas, Robert Fet al. In vitro aspirin resistance detected by PFA-100 closure time: pivotal role of plasma von Willebrand factor. Br J Haematol 2004; 124 (1):80-5.

\section{References}

1. Bae M.H., Lee J.H., Yang D.H. et al. White blood cell, hemoglobinand platelet distribution width as short-term prognostic markers in patients withacute myocardial infarction. J. Korean Med. Sci., 2014, 29(4), pp. 519-26.

2. Becatti M., Fiorillo C., Gori A.M. et al. Platelet and leukocyte ROS production and lipoperoxidation are associated with high platelet reactivity in Non-ST elevation myocardial infarction (NSTEMI) patients on dual antiplatelet treatment. Atherosclerosis. 2013, 231(2), pp. 392-400.

3. Grinshtein Yu.I., Savchenko A.A., Grinshtein I.Yu., Savchenko E.A. Osobennosti gemostaza, metabolicheskoy aktivnosti trombotsitov i chastota rezistentnosti k aspirinu u bol'nykh s khronicheskoy serdechnoy nedostatochnost'yu posle aortokoronarnogo shuntirovaniya [Features of hemostasis, metabolic activity of platelets and the frequency of aspirin resistance in patients with chronic heart failure after coronary artery bypass surgery]. Cardiology, 2008, № 6, pp. 51-56.

4. 2013 ESC Guidelines on the Management of Stable Coronary Artery Disease. The Task Force on the management of stable coronary artery disease of the European Society of Cardiology. Russ J Cardiol 2014, 7 (111): 7-79.

5. Grinshtein Yu.I., Filonenko I.V., Savchenko A.A. et al. Sposob diagnostiki rezistentnosti $\mathrm{k}$ acetilsalicilovoj kislote. [A method for diagnosing resistance to acetylsalicylic acid.] Patent № 2413953 Russia, MPK G01N 33/86 (2006.01). Published 10.03.2009, Bul. № 7: 8 p. Ruusia. 
6. Savchenko E.A., Savchenko A.A., Gerasimchuk A.N., Grischenko D.A. Otsenka metabolicheskogo statusa trombotsitov v norme i pri ishemicheskoy bolezni serdtsa [Evaluation of the metabolic status of platelets in normal and coronary heart disease.] Clinical laboratory diagnostics, 2006, № 5, pp. 33-36.

7. Borna C., Lazarowski E., van Heusden C. et al. Resistance to aspirin is increased by ST-elevation myocardial infarction and correlates with adenosine diphosphate levels. Thromb J., 2005; 3:10.

8. Chakroun T., Gerotziafas, Robert Fet al. In vitro aspirin resistance detected by PFA-100 closure time: pivotal role of plasma von Willebrand factor. Br J Haematol 2004; 124 (1):80-5.

\section{ДАННЫЕ ОБ АВТОРАХ}

Гончаров Максим Дмитриевич, врач

Федеральный центр сердечно-сосудистой хирургии МЗ РФ

ул. Караульная, 45, г. Красноярск, 660020, Российская Федерачия adimax07@mail.ru

Веселов Андрей Евгеньевич, аспирант

Научно-исследовательский институт медицинских проблем Севера ФИЦ КНЦ СО РАН

ул. Партизана Железняка, 32, г. Красноярск, 660022, Российская Федераиия

Veselov.a93@mail.ru

Пац Юрий Степанович, профессор

Красноярский государственный медииинский университет имени профессора В.Ф. Войно-Ясенеикого МЗ РФ

ул. Партизана Железняка, 1а, г. Красноярск, 660022, Российская Федераиия

y.patz@mail.ru

\section{DATA ABOUT THE AUTHORS}

\section{Goncharov Maxim Dmitrievich, doctor}

Federal Center for Cardiovascular Surgery, Ministry of Health of the Russian Federation

45, Karaulnaya str., Krasnoyarsk, 660020, Russian Federation adimax07@mail.ru 
Veselov Andrey Evgenievich, graduate student

Scientific Research Institute of Medical Problems of the North 3g, Partizan Zheleznyak Str., Krasnoyarsk, 660022, Russian Federation Veselov.a93@mail.ru

ORCID: 0000-0003-2500-3809

Pats Yury Stepanovich, professor

Krasnoyarsk State Medical University named after professor V.F. Voyno-Yasenetsky Ministry of Health of the Russian Federation

1a, Partizan Zheleznyak Str., Krasnoyarsk, 660022, Russian Federation y.patz@mail.ru 